\title{
Creative-thinking about Lacquer Cultural Industry in Fuzhou
}

\author{
Jian Zhang \\ Xiamen Academy of Arts and Design \\ Fuzhou University \\ Xiamen, Fujian, China 361024
}

\begin{abstract}
The article analysis the Fuzhou lacquer industry thoroughly based on the framework of modern creative cultural industry. It combs Fuzhou lacquer ware development history firstly, and then outlines the current problems which the lacquer industry revitalization is facing. It presents an opinion that the heart of future developments may change from lacquer ware industry to lacquer cultural industry, and may awake to the importance of establishing a good image for Fuzhou lacquer culture. It also provides some reasonable suggestions of market analysis, product design and marketing development.
\end{abstract}

Keywords-Fuzhou lacquer industry; cultural industry; creativity

\section{INTRODUCTION}

Fuzhou lacquer industry flourished in the middle period of the Qing Dynasty. After Shen Shaoan, Fuzhou lacquer achieved remarkable success in China's industrial art field, especially in the late Qing Dynasty and the early Republic of China, Fuzhou lacquer won several awards in World Expo and gradually formed distinctive worldwide cultural industry, becoming a flag in our country's industrial art field (one of the three treasure's of China's industrial art); since new China was founded, supported by policies, the first and second bodiless lacquer factory founded in Fuzhou propelled Fuzhou lacquer industry to a peak; however, after entering 1990s, as China's great industrial system was gradually established, the old production method of lacquer no longer fit the economic development, and Fuzhou's lacquer factories both closed down, which declared the death of traditional industrial art product mode.

Entering the new century, on the background of international society's culture protection, China gradually paid attention to inheritance and protection of traditional industrial culture, and Fuzhou lacquer was listed in the first batch of national nonmaterial cultural heritage list; our province also took the protection of lacquer culture as an important work, and set up Fuzhou lacquer protection base based on the former second bodiless lacquer factory, gathering part of lacquer workshops, re-establishing industry association, launching allowance system for masters apprenticing, integrating industry, university and research to promote the development of lacquer industry. It hopes to inherit and develop Fuzhou lacquer industry with the integration of resources; at the same time, Fuzhou held "2010 China Fuzhou International Lacquer
Culture Inheritance and Innovation Summit Forum" and "Coming from Hemudu, 2010 3rd International Lacquer Art Exhibition" held by Lacquer Art Committee of China National Arts and Crafts Society and Fuzhou City, reshaping the image of important city of lacquer culture for Fuzhou. However, can Fuzhou lacquer industry revive by merely above measures and policies? The author doubts this.

\section{PRoBlems THAT THE LACQUER CULTURAL INDUSTRY FACES}

The above measures are merely the protection and inheritance of traditional lacquer culture essentially, which can't not be considered as the development of industry, and the reasons are as follows:

\section{A. The Old Production and Manufacturing Mode Are Not Changed}

The basic technology and process of lacquer manufacturing in current workshops or lacquer protection base are the same as that of tens of years ago, which is nothing but making mud draft, turning over formwork, mounting, coarse paint, breaking away from body and painted finishes; it executes line production in factory of breaking away from body, so there are few lacquerers who are able to master the whole set of manufacturing technology of lacquer, which leads to these or those problems during production and manufacturing in lacquer workshops.

\section{B. The Old Industry Property Is Not Changed}

At present, the lacquer industry still continues traditional production mode, and the way and method of all the lacquer workshops, lacquer protection bases and other organizations related to Fuzhou lacquer to work on revival of industry, namely the cognition of industry property have deviation, which takes the way of traditional arts and crafts industry and doesn't fuse modern industry concept into the production of lacquer industry, and so the lacquer produces is similar to product modeled after an antique and lacks sense of the time.

\section{The Old Production Concept Is Not Changed}

The industry doesn't realize that the development of the current social-cultural system has different cognition of lacquer industry. Firstly it is the change of demand, after 
industrial system replacing technological system, most household articles are replaced by industrial products, and the rate of traditional industrial art products in daily necessities decreases rapidly, and plastic products occupy lacquer market; secondly, it is the influence of economic factors. The manufacture cost of lacquer is high, whose material comes from single channel, which leads to high price of lacquer, and citizens' desire of lacquer is thus suppressed. For example, there is no lacquer tree in Fujian, and the raw lacquer had to be delivered from Sichuan, Hu'nan and Hubei, which increases cost virtually; there are only a limited number of raw lacquer factories in Fujian now, and the only one with large scale is Jianlian Raw Lacquer Factory in Cangshan, Fuzhou. Other manufacturing materials such as gypsum and grass cloth also increase their prices. In general, the development of lacquer market is not as ideal as expected; lastly it is the change of aesthetic taste, after he reform and opening-up policy, the country is open, and countrymen's concept of life and even values change with the continuous fusion of Chinese and western cultures. In the aspect of household vessels, people tend to prefer products with strong practicability, abundant shapes and characteristics of age, and Fuzhou lacquer exactly satisfies people's demand, which is also one of the reasons why two lacquer factories in Fuzhou close down. The production of Fuzhou lacquer can still not break this disadvantage now and deviates from the track of beauty of life.

\section{INNOVATIVE IDEA OF LACQUER CULTURAL INDUSTRY}

The above problems cause the industrialization of Fuzhou lacquer to come to a standstill, and the revitalization and revival of Fuzhou lacquer industry does not fit the development of the time. In consideration of the development strategy of creating Fujian's cultural industry at present and the appeal of taking cultural and creative industry as the mainstay industry of province, it shall transform the development focus of Fuzhou lacquer industry from lacquer industry to lacquer cultural industry, excavate the connotation of lacquer industry, expand the outreach of lacquer industry, carry forward tradition and blaze new trails in a pioneering spirit at the same time, create brand new Fuzhou lacquer cultural industry and conduct market research and analysis on it, figure proper and scientific marketing positioning, and adjust the design idea and style of cultural products based on marketing positioning. Surely it will promote Fuzhou lacquer cultural industry to a new starting point via convenient method of market expansion.

Based on the author's investigation and survey on the production situation of Fuzhou lacquer workshops, I can get initial assessment to the development of Fuzhou lacquer cultural industry. At present, Fuzhou lacquer culture market is different from the lacquer market in old mode of planned economy, so it must reposition the lacquer cultural products now to meet the demand of market. Roughly, lacquer cultural products are divided into following types:

\section{A. Business Supplies}

The demand of modern business supplies is rigid, and almost all the companies will purchase certain quantity of supplies to use in ceremony, conference or to send to client, partner, guest and inner employee during activity, which offers business opportunity to lacquer cultural industry. The goal of business supplies is to advertise the company image, conference of activity theme. Thus, it shall combine the company image and main product in manufacture of lacquer cultural products, select themes and contents related to festival, company meeting or activity to develop products.

\section{B. Tourist Goods}

Tourist goods serves as either souvenir or gift, so it has to be portable and its cost shall be controlled, too. Its sales network generally distributes around scenic spots. Apart from ornament and small artware, it can also be practical goods such as business card holder, jewelry, pendant and so on. Of course, as tourist goods, lacquer cultural product shall show the feature Fuzhou's tourist culture. The cultural images like three lanes and seven alleys, Drum Mountain, Xichan Temple and other symbols which can show Fuzhou's special culture as theme and content of development of lacquer cultural products.

\section{Household Products}

The system of modern household products is large and multiple, including furniture, tea set, tableware, flower implement, clock, ornament, jewelry, pendant, photo frame, magazine rack, storage box, office supplies, kitchen supplies and bathroom accessories, which expands space for Fuzhou lacquer cultural industry because the lacquer owns the advantages of light, solid, soaking resistant, nondeformable, fadeless and acid and alkali resistant. It can develop and innovate material and technology of traditional lacquer to apply to production of household supplies.

\section{The Detailed Measures of INNOVATION OF LACQUER CULTURAL INDUSTRY}

The inheritance and development of modern Fuzhou lacquer industry shall open mind and vision, target at development of social culture, fuse development of existing lacquer industry and cultural industry, take the way of cultural creative industry, apply manufacturing technology of lacquer to wider fields, take the way of crossing industry, and only then can it play the role of traditional lacquer culture.

\section{A. Pay Attention to the Design of Cultural Products}

In the development of Fuzhou lacquer cultural industry, design of lacquer cultural products comes after positioning of product. At present, the expansion of Fuzhou lacquer industry market is not smooth, of which the backward design is an important reason, and this is particularly obvious in Fuzhou lacquer workshops. The design of shape, pattern, color and material matching of the lacquer cultural product is related to the development of lacquer cultural industry.

Of course, the innovation of design of the lacquer cultural product shall firstly deeply understand the traditional technology of Fuzhou lacquer. The deep root of why modern products can't break away from old form and expression is that it does not deeply understand the essence of the tradition. The shape and ornamentation of lacquer products in different ages are "meaningful forms", which contain special cosmic consciousness, life sentiment, political authority and social 
ethics. Thus it shall fully understand the life style of modern people and essence of social culture while learning the technology essence of Fuzhou traditional lacquer, dialectically apply special Chinese creating principle, design and manufacture products that fit life style and aesthetic interest of modern people. It shall also keep learning relevant new knowledge and new technology, introduce concept of modern industrial design, learn and master method of modern digital design and digital processing, learn from others' strong points to offset one's weakness, improve the efficiency of development and production of new products based on advanced design and manufacture technology, create new lacquer products which fit modern fashion, own strong industrial beauty, contain traditional cultural spirit based on traditional technology features. Besides, it also needs to pay attention to new trends of market and follow it.

In the aspect of design of lacquer cultural product, only attention is not enough, what matters is large quantities of talents who work on design of lacquerware, which needs to cooperate with art \& design colleges, such as setting up lacquer culture creativity design major in art \& design colleges in our province, introduction concept of modern design to education, pay attention to both the cultivation of students' cognition of lacquer culture and students' design ability, cultivate reserve talents for the development of Fuzhou lacquer cultural industry.

\section{B. Expand the Market of Lacquer Cultural Industry}

"Even savoury and mellow wine is afraid of deep alley", market expansion is also an important step of development of lacquer cultural industry. Compared to the past when Fuzhou lacquer depended on retailers and agents to hawk, modern market promotion methods are more diversified. The author thinks that the following methods can further expand the market of Fuzhou lacquer cultural industry:

1) Take use of information technology: Displaying the products on line and selling is a popular business practice nowadays, whose operation cost is low. At the same time, Internet is a public publicity medium, the history, technology, material feature, producing process of Fuzhou lacquer and appreciation of competitive lacquer products can all be introduced and spread on line. Via on-line interaction platform, the marketing personnel can also communicate with clients, understand their demand and feed the information back to designers of the R\&D department in time. The website of Fuzhou lacquer culture shall be elaborately made, updated and maintained in time, and shall have professional web links and professional personnel to take in charge of online sales and response to customers.

2) Combine with tourist industry: Fujian has abundant tourism resource and broad prospects of tourist market. Fuzhou lacquer cultural industry shall combine with tourist industry, develop tourist projects of visiting the manufacturing process of lacquer in traditional technology, let tourists understand the manufacturing process of lacquer products, feel the exquisite skills of lacquer artificers and the long production cycle and large labor of lacquer. Other tourist projects can also combine with introduction of Fuzhou lacquer cultural industry, such as organizing tourists visiting scenic spots related to the themes expressed by Fuzhou lacquer. These measures can let the public truly feel the value of Fuzhou lacquer culture.

3) Pay attention to shopping guide of lacquer cultural product: cultivate professional salesmen of Fuzhou lacquer cultural product, teach them with technology process and special skill of lacquer production; the producing area, feature and value of raw material; the style and feature of the design; and lacquer culture knowledge such as appreciation and protection of lacquer. In this way, consumers will know more about Fuzhou lacquer, and understand the inner value of Fuzhou lacquer cultural product from various aspects such as history, culture, collection, art and practicability.

4) Adopt experiential marketing approach: The experiential marketing approach is popular at present, which can be introduced to marketing of Fuzhou lacquer cultural product. We can decorate the shopping place of household lacquerware into several prototype rooms in different styles, and display the lacquer in domestic environment and scenes of life, where consumers can easily feel the style of products. For example, display decorative picture with lacquer art, lacquer furniture, lacquer screen, lamp with lacquer art and lacquer tea sets in the same space to attract consumers' attention to Fuzhou lacquer cultural industry.

\section{CONCLUSION}

In conclusion, the creation of Fuzhou lacquer cultural industry is complicated but full of opportunities, as long as we have sufficient passion, ideal exploration and scientific method and give it more space, Fuzhou lacquer cultural industry still has a bright future.

\section{REFERENCES}

[1] Fuzhou Industrial Art Bureau, Category of leader's guidance, “The first draft of 'History of bodiless lacquer industry of Fuzhou' of All-China Federation of Industry and Commerce", Fuzhou Archives, Fonds No.: 55, Cat. No.: 2, File No.: 44, 1963.7. P17.

[2] Fuzhou Industrial Art Bureau, Category of Technology, "The bureau's summary plan of work on improving management of art creation", Fonds No.: 55, Cat. No.: 2, File No.: 55, 1963.7.12. P22.

[3] Statistics Department Fuzhou Municipal Government, "Survey report on bodiless lacquer industry in Fuzhou", Fonds No.: 180, Cat. No.: 5, File No.: 77, Fujian Archives, 1954.11.19. P3 